\title{
Successful treatment of two cases of
}

\section{urorectal septum malformation sequence with oligohydramnios and severe respiratory failure}

This article was published in the following Dove Press journal:

Research and Reports in Neonatology

2 March 2013

Number of times this article has been viewed

\author{
Kazuhito Sekiguchi \\ Daijiro Takahashi \\ Takehiko Hiroma \\ Tomohiko Nakamura \\ Division of Neonatology, Nagano \\ Children's Hospital, Nagano, Japan
}

Correspondence: Tomohiko Nakamura Division of Neonatology, Nagano Children's Hospital, 3100 Toyoshina, Nagano 399-8288, Japan Email tnakamura@naganoch.gr.jp

\begin{abstract}
Urorectal septum malformation sequence can be diagnosed prenatally. We report herein the successful treatment of severe respiratory failure in two patients with urorectal septum malformation sequence and prenatally diagnosed oligohydramnios. The patients showed significant hypoxic deterioration and persistent pulmonary artery hypertension soon after birth. We used high-frequency ventilation (HFO), nitric oxide (NO), and extracorporeal membrane oxygenation (ECMO). The patients were successfully weaned from ECMO and artificial ventilation and discharged to home. Although termination of the pregnancy has often been selected for fetuses with oligohydramnios-related urorectal septum malformation sequence, our results suggest the opportunity for these fetuses to be treated using respiratory supports including HFO, $\mathrm{NO}$, and ECMO after birth.
\end{abstract}

Keywords: urorectal septum malformation sequence, oligohydramnios, pulmonary hypoplasia

\section{Case reports Case I}

A $2.4 \mathrm{~kg}$ girl was delivered in our institution by cesarean section in gestational week 36 because of placenta abruption. Urinary tract obstruction with vesico-intestinal fistula had been diagnosed antenatally. Her mother had no history of special medications, infections, or genetic family history of vesico-intestinal fistula. The mother had been diagnosed with oligohydramnios due to suspected fetal urogenital anomaly in gestational week 25 . We did not perform any chromosomal or fluorescence in situ hybridization (FISH) analysis prenatally. After delivery, the neonate was immediately intubated due to respiratory failure and admitted to our neonatal intensive care unit (NICU). Apgar scores were five at 1 minute and eight at 5 minutes. Initial chest X-ray showed pneumothorax and small lung (Figure 1). After starting high-frequency oscillation (HFO) mode (Cariope; Metran, Saitama, Japan) with mean airway pressure $20 \mathrm{~cm}$ $\mathrm{H}_{2} \mathrm{O}$, oxygen index was 20.0. During medical stabilization, the best preductal $\mathrm{PaO}_{2}$ was $145 \mathrm{mmHg}$, with a $\mathrm{PaCO}_{2}$ of $51.4 \mathrm{mmHg}$.

At 2 hours old, progressive hypoxia developed with a postductal arterial oxygen saturation of $82 \%$. Echocardiography revealed supersystemic pulmonary artery pressures and tricuspid regurgitation, and chest radiography showed bilateral pneumothorax. After bilateral drainage of the thoracic cavity, nitric oxide (NO) therapy was started at $20 \mathrm{ppm}$. However, hypoxia with a preductal $\mathrm{PaO}_{2}$ of $33.6 \mathrm{mmHg}$ remained unimproved, despite increasing NO concentration to $40 \mathrm{ppm}$ at 3 hours old. The oxygenation index was 44.6. Standard venovenous extracorporeal membrane oxygenation (ECMO) was started with continuous hemodiafiltration at 14 hours old. Static lung compliance was submit your manuscript | www.dovepress.com

Dovepress

http://dx.doi.org/10.21 147/RRN.S40497
Research and Reports in Neonatology 2013:3 I-4

(C) 2013 Sekiguchi et al, publisher and licensee Dove Medical Press Ltd. This is an Open Access article which permits unrestricted noncommercial use, provided the original work is properly cited. 


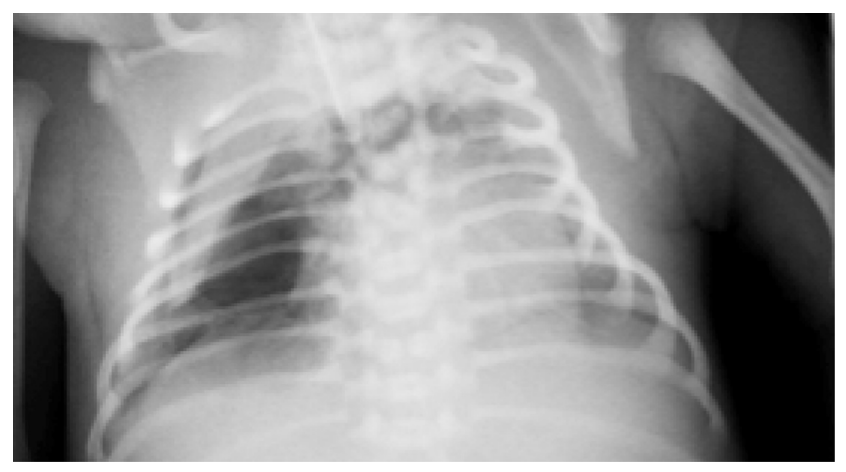

Figure I Chest X-ray from Case I on admission.

$0.07 \mathrm{~mL} / \mathrm{cm} \mathrm{H}_{2} \mathrm{O} / \mathrm{kg}$ before ECMO, as measured using a pneumotachograph (ARFEL-VR ${ }^{\circledR}$; Aivision, Tokyo, Japan) with the passive expiratory flow technique. After starting ECMO, oxygenation index started improving. After 70 hours on ECMO, the infant was successfully weaned from ECMO with a postductal $\mathrm{PaO}_{2}$ of $123 \mathrm{mmHg}$, and a $\mathrm{PaCO}_{2}$ of $33.6 \mathrm{mmHg}$. Static lung compliance was $0.36 \mathrm{~mL} / \mathrm{cm} \mathrm{H}_{2} \mathrm{O} / \mathrm{kg}$ at that time. NO therapy was temporarily reinstituted, but discontinued after 2 days. From 9 days old, the patient was ventilated with intermittent mandatory ventilation. Progressive weaning from ventilator support was initiated, with the infant successfully extubated at 11 days old. Static respiratory compliance was $0.62 \mathrm{~mL} / \mathrm{cm} \mathrm{H}_{2} \mathrm{O} / \mathrm{kg}$ at that time.

Surgery was performed at 15 days old. A large fistula, $2.5 \mathrm{~cm}$ in diameter, was identified connecting the cecum to the back of the bladder. The colon continued for about $6 \mathrm{~cm}$ beyond the fistula before ending blindly. On both sides of the bladder, a uterus, uterine tube, and ovary were present (Figure 2). The cecovesical fistula was divided, the gaps in the bladder and cecum were sutured, and end colostomy was

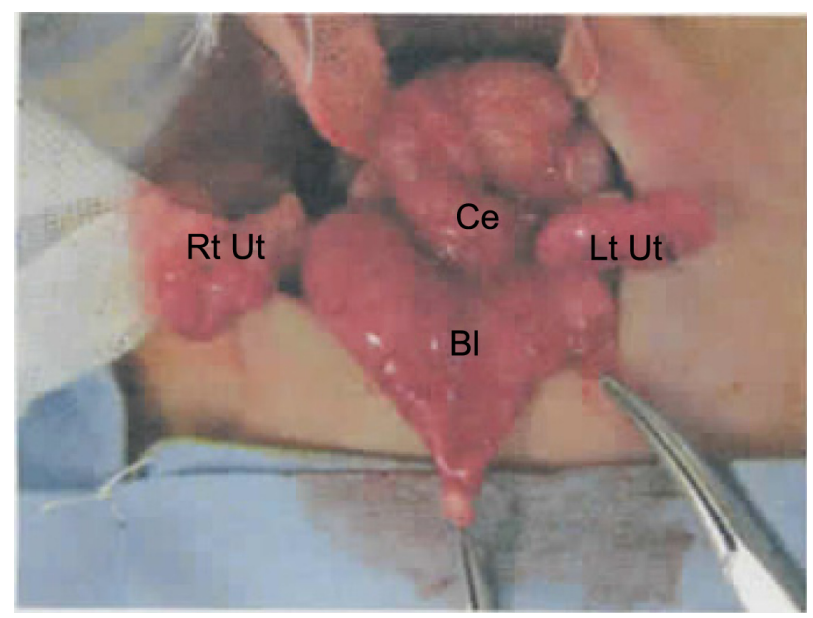

Figure 2 Photograph from Case I in operation.

Abbreviations: $\mathrm{Bl}$, bladder; $\mathrm{CE}$, cecum; $\mathrm{LT}$, left; Rt, right; Ut, uterus. performed. Although total urinary incontinence was present, renal function was maintained and the postoperative course was otherwise uneventful during the neonatal period. The patient was discharged at 42 days old. She had a second operation to repair the colon at 6 months old and showed good development.

\section{Case 2}

A $2.5 \mathrm{~kg}$ girl was delivered vaginally in gestational week 37 due to spontaneous labor. Bilateral renal hypoplasia had been diagnosed antenatally. The mother had been diagnosed with oligohydramnios due to suspected fetal urogenital anomaly in gestational week 25 . The mother had no history of special medications, infections, or genetic family history of vesico-intestinal fistula. We did not perform any chromosomal or FISH analysis prenatally. Apgar scores were seven at 1 minute and eight at 5 minutes. A single hole with leakage of meconium-stained urine was noticed in the perineal region, but no anus was present. Bilateral renal hypoplasia was apparent on ultrasonography. The infant was immediately intubated and mechanical ventilation was started due to respiratory failure. Chest radiography showed right pneumothorax (Figure 3). She was then transferred to our NICU and ventilation was initiated using the HFO mode. After starting HFO mode (Cariope) with mean airway pressure $15 \mathrm{~cm} \mathrm{H}_{2} \mathrm{O}$, oxygen index was 15.0. During medical stabilization, the best preductal $\mathrm{PaO}_{2}$ was $353 \mathrm{mmHg}$ with a $\mathrm{PaCO}_{2}$ of $38.6 \mathrm{mmHg}$.

At 9 hours old, progressive hypoxia developed with a postductal arterial oxygen saturation of $88 \%$, despite $\mathrm{FiO}_{2}$ of 1.0. Echocardiography revealed supersystemic pulmonary artery pressures and tricuspid regurgitation, so NO therapy

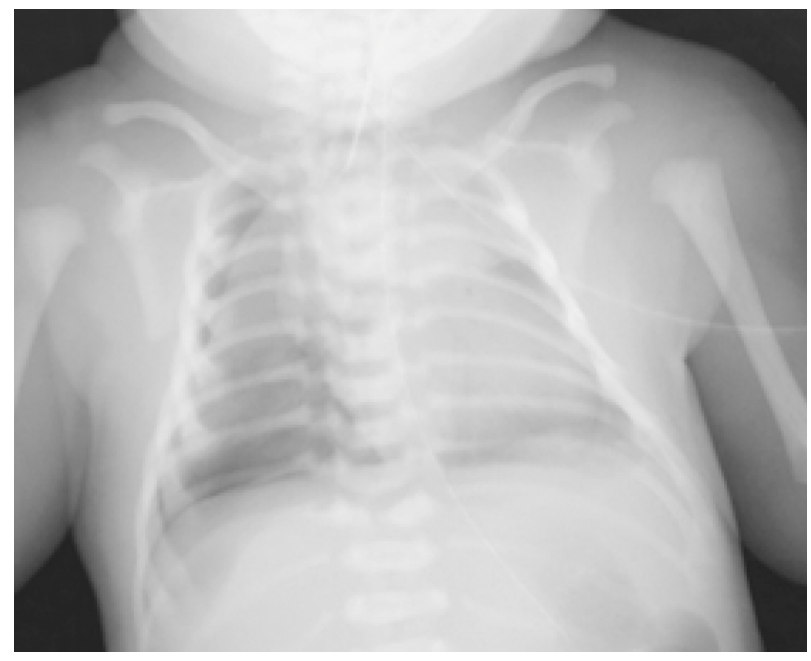

Figure 3 Chest $\mathrm{X}$-ray from Case 2 on admission. 
was started at $20 \mathrm{ppm}$. However, hypoxia with a preductal $\mathrm{PaO}_{2}$ of $36.4 \mathrm{mmHg}$ at an $\mathrm{FiO}_{2}$ of 1.0 remained unimproved. The oxygenation index was 46.7. Standard arterio-venous ECMO was started with continuous hemodiafiltration at 26 hours old. Static lung compliance was $0.08 \mathrm{~mL} / \mathrm{cm}$ $\mathrm{H}_{2} \mathrm{O} / \mathrm{kg}$ before ECMO, as measured using the ARFEL-VR ${ }^{\circledR}$ pneumotachograph (Aivision). After ECMO was started, oxygenation index improved. After 23 hours of ECMO, the infant was successfully weaned from ECMO with a postductal $\mathrm{PaO}_{2}$ of $238 \mathrm{mmHg}$ and a $\mathrm{PaCO}_{2}$ of $26.6 \mathrm{mmHg}$. Static lung compliance was $0.53 \mathrm{~mL} / \mathrm{cm} \mathrm{H}_{2} \mathrm{O} / \mathrm{kg}$ at that time. NO was temporarily reinstituted, but discontinued at 4 days old. From 9 days old, the infant was ventilated using intermittent mandatory ventilation. Progressive weaning from ventilator support then ensued, and the infant was successfully extubated at 23 days old with respiratory compliance at $1.16 \mathrm{~mL} / \mathrm{cm} \mathrm{H}_{2} \mathrm{O} / \mathrm{kg}$.

Percutaneous cystostomy was performed at 1 day old, followed by colostomy at 15 days old. Laboratory data indicated progression of renal failure, with a blood urea nitrogen level of $85 \mathrm{mg} / \mathrm{dL}$ and a creatinine level of $6.1 \mathrm{mg} / \mathrm{dL}$. Peritoneal dialysis was started at 50 days old. The infant subsequently showed good feeding and weight gain. She was discharged with in-home peritoneal dialysis at 4 months old. She needs renal transplantation in the near future.

\section{Discussion}

Urorectal septum malformation sequence with oligohydramnios is usually a lethal anomaly due to pulmonary hypoplasia. Wheeler et al reported and reviewed 62 cases of urorectal septum malformation sequence. ${ }^{1}$ Lung hypoplasia was noticed in $80 \%$ of urorectal septum malformation sequence patients. Only three of 62 patients had long-term survival. The three patients who survived did not have pulmonary hypoplasia, and severe oligohydramnios was not reported. Adequate quantities of amniotic fluid are required for satisfactory development of the fetal lung. ${ }^{2,3}$ Urorectal septum malformation sequence should be differentiated prenatally from other conditions offering better prognosis, such as obstructive uropathies and persistent cloaca. ${ }^{4}$ However, neonatal respiratory management has achieved marked advances recently, particularly for sick neonates with severe respiratory failure. Oligohydramnios-related pulmonary hypoplasia can present as severe respiratory failure leading to early neonatal death, as respiratory insufficiency with pulmonary hemorrhage, bronchopulmonary dysplasia, or subacute lung disease, or as mild or even transient respiratory disease. Perinatal mortality rates approximate $70 \%$ in most series (55\%-100\%). ${ }^{5}$ Furthermore, some studies have suggested that mechanical ventilation of the hypoplastic lungs actually contributes to the impairment of subsequent alveolar development. ${ }^{6}$ Antenatal diagnosis is very important to facilitate the planning of optimal perinatal care and counseling with families.

Neonatal respiratory management has achieved marked advances recently, particularly for sick neonates with severe respiratory failure. Management techniques for oligohydramnios-related pulmonary hypoplasia and persistent pulmonary hypertension include HFO, NO, and ECMO. We achieved successful treatment using HFO, NO, and ECMO in two patients with severe oligohydramnios-related respiratory failure caused by urorectal septum malformation sequence in which static respiratory compliances were 0.07 and $0.08 \mathrm{~mL} / \mathrm{cm} \mathrm{H}_{2} \mathrm{O} / \mathrm{kg}$ at birth. Although termination of the pregnancy has often been selected for fetuses with oligohydramnios-related urorectal septum malformation sequence, our results suggest the opportunity for these fetuses to be placed on respiratory support, including NO and ECMO, after birth.

\section{Acknowledgment}

This study was funded by a grant for scientific research by the Ministry of Health and Welfare of Japan.

\section{Disclosure}

The authors report no conflicts of interest in this work.

\section{References}

1. Wheeler PG, Weaver DD, Obeime MO, Vance GH, Bull MJ, Escobar LF. Urorectal septum malformation sequence: report of thirteen additional cases and review of the literature. Am J Med Genet. 1997; 73(4):456-462.

2. Perlman M, Levin M. Fetal pulmonary hypoplasia, anuria, and oligohydramnios: clinicopathologic observations and review of the literature. Am J Obstet Gynecol. 1974;118(8):1119-1123.

3. Thomas IT, Smith DW. Oligohydramnios, cause of the nonrenal features of Potter's syndrome, including pulmonary hypoplasia. J Pediatr. 1974;84(6):811-815.

4. Bargaje A, Yerger JF, Khouzami A, Jones C. Cloacal dysgenesis sequence. Ann Diagn Pathol. 2008;12(1):62-66.

5. Laudy JA, Wladimiroff JW. The fetal lung 2: Pulmonary hypoplasia. Ultrasound Obstet Gynecol. 2000;16(5):482-494.

6. Hislop AA, Wigglesworth JS, Desai R, Aber V. The effects of preterm delivery and mechanical ventilation on human lung growth. Early Hum Dev. 1987;15(3):147-164. 


\section{Publish your work in this journal}

Research and Reports in Neonatology is an international, peer-reviewed, open access journal publishing original research, reports, editorials, reviews and commentaries on neonatal health. The manuscript management system is completely online and includes a very quick and fair peer-review system. Visit http://www.dovepress.com/testimonials.php to read real quotes from published authors. 